Historia
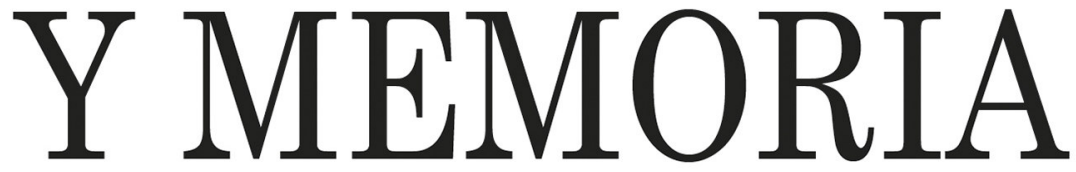

ISSN: 2027-5137 Julio - Diciembre, Año 2016 - Tunja, Colombia

O papel dos directores de fotografia no cinema: entrevista a Acácio de Almeida e Abel Aboim

Maria Raquel Paulo Rato Alves

Páginas: 333 - 350

DOI: http://dx.doi.org/10.19053/20275137.4462

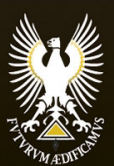




\title{
O papel dos directores de fotografia no cinema: entrevista a Acácio de Almeida e Abel Aboim*
}

\author{
Maria Raquel Paulo Rato Alves ${ }^{1}$ \\ Lisboa, Março10 de 2010
}

DOI: http://dx.doi.org/10.19053/20275137.4462

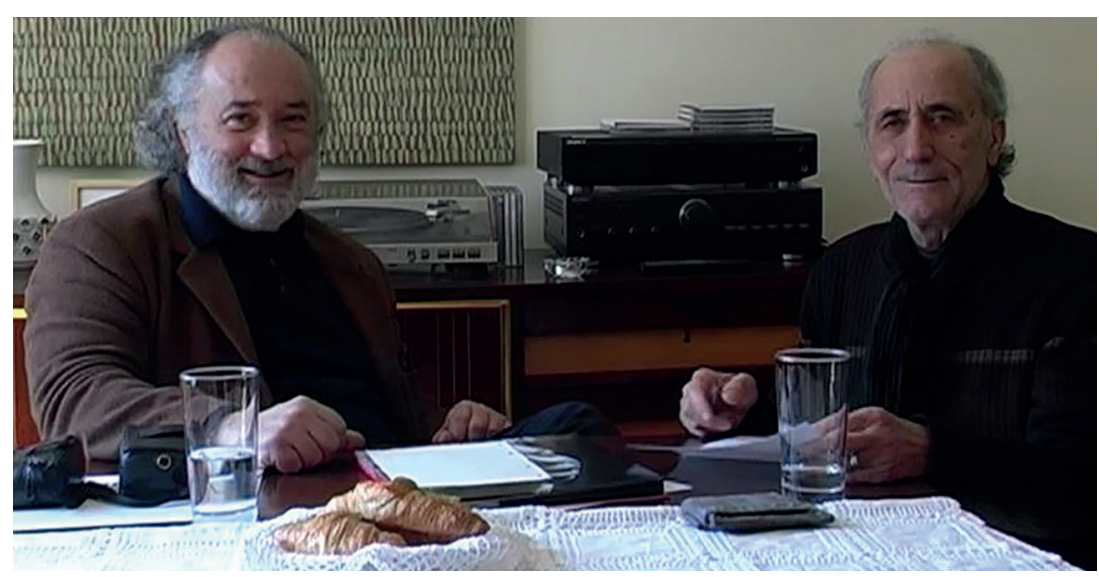

Imagem 1. Do lado esquerdo, Abel Aboim e à direita Acácio de Almeida Fonte: Fotograma do vídeo realizado por Raquel Rato.

\section{Introdução}

A presente entrevista realizada a Acácio de Almeida e Abel Aboim pretende mostrar o papel fundamental do director de

\footnotetext{
* Entrevista realizada por Raquel Rato ao director de fotografia Acácio de Almeida e ao professor Abel Aboim a 10 de Março de 2010 em Lisboa.

1 Raquel Rato, nasceu na Covilhã - Portugal em 1971. Licenciada em Cinema Ramo de Realização e Animação Sócio-cultural, em 2007 termina um mestrado (DEA) na Universidade de Salamanca em Audiovisual e Publicidade. Em Dezembro de 2013 obtém o grau de doutora em Cínema Audiovisuel pela Universidade de Paris 3 Sorbonne Nouvelle. Especializada na direcção de fotografia, participa regularmente em colóquios e conferências nacionais e internacionais. Actualmente, é Investigadora integrada do IHC (Instituto de História Contemporânea) da Faculdade de Ciências Sociais e Humanas da Universidade Nova de Lisboa, com actividade de investigação no domínio da História Oral do cinema português.
} 
fotografia na realização de um filme. O director de fotografia, é um dos elementos imprescindíveis à realização e à boa recepção de ma obra cinematográfica. Não é exagero dizer-se que a eficácia das imagens de um filme passa, pelo trabalho do director de fotografia.

O director de fotografia Acácio de Almeida², uma das figuras mais emblemáticas da história do cinema português com renome internacional, que trabalhou com grandes realizadores tais como: António Reis; Raúl Ruiz; João César Monteiro; Teresa Villaverde; Alain Tanner etc. O seu trabalho esteve na base do sucesso que muitos filmes obtiveram. É um director de fotografia que no meio de grandes criadores tem um enorme destaque na sua actividade de "artesão da luz", pois tem particularidades que o diferencia e que o torna único na invenção de meios e no acto criativo. Pode dizer-se que tem uma "marca" muito forte que o distingue e que o aproxima dos grandes mestres da direcção de fotografia mundial. Acácio de Almeida, iniciou muitos realizadores portugueses, vindo estes a terem um percurso de autor. Formando os seus primeiros olhares, que vieram a realizar um cinema de autor reconhecido pelo grande público. As experiências artísticas de Acácio de Almeida são únicas e de uma riqueza singular que, se tornou urgente pesquisar e teorizá-las para que um dia sejam transmitidas e conhecidas dentro do contexto cinematográfico nacional e internacional. Acácio de Almeida foi ainda fundador do Centro Português de Cinema em 1970 e da Cooperativa Grupo Zero após o 25 de Abril de 1974.

2 Acácio de Almeida, nasceu em São João da Pesqueira (Trás-os-Montes é a denominação de uma região de Portugal, que, por diversas vezes constituiu uma província, com limites e atribuições, que foram variando ao longo da história. Foi também uma das regiões administrativas da proposta de regionalização rejeitada em Referendo em 1998. É uma das regiões de Portugal com maior número de emigrantes e uma das que mais sofrem com o despovoamento. $\mathrm{O}$ seu isolamento secular permitiu porém a sobrevivência de tradições culturais que marcam a identidade portuguesa. É, por isso e pela sua beleza natural, um objecto fetiche do cinema português). a 28 de Maio de 1938, num ambiente rural, rodeado de natureza. Sempre o fascinou a luz do fogo da lareira e as sombras que se formavam com essa luz. Era uma criança feliz. Aos 8 anos descobriu o cinema, através de um projeccionista que andava pelas aldeias, o chamado cinema ambulante. Para ele a luz, é a memória da sua infância, todo o seu trabalho é influenciado por ela. As imagens da sua infância, com as suas matizes, com as suas luzes marcaram-no na sua arte de iluminar. 
Em 1970 foi bolseiro da Fundação Calouste Gulbenkian em Paris onde teve a oportunidade de estagiar com um mestre da fotografia cinematográfica, Nestor Almendros. Fundou também a produtora Inforfilmes em 1987, produzindo e coproduzindo diversos filmes.

João Abel Aboim ${ }^{3}$ é profissional de cinema nas áreas de imagem e realização. Iniciou-se no cinema como assistente no filme "O Recado» de José Fonseca e Costa. Cumpriu o serviço militar no Serviço Cartográfico do Exército, de 1971 a 1974, onde tirou a especialidade de fotografia e cinema e dirigiu curtas-metragens para o exército. Foi sócio fundador de Cinequanon, em 1974. Ingressou no ano seguinte no Núcleo de Produção do IPC (instituto Português de Cinema) onde se manteve até à sua extinção em 1976. Participa então na fundação da Prole Filme. Foi director de fotografia de longas, médias e curtas-metragens. Realizou e fotografou vários filmes documentais. Foi professor na E.S.T.C. (Escola Superior de Teatro e Cinema) na área de imagem, durante mais de três décadas.

\section{Entrevista}

No ano de 2015, a convite do Centro Cultural de Belém (inserido no Ano Internacional da Luz) realiza uma exposição chamada: O elogio da luz e da sombra. A exposição aborda e questiona o trabalho técnico/artístico que estes "fazedores de imagens", em geral, desenvolvem durante a produção de um filme. Para o director de fotografia: "o contributo $e$ a importância do trabalho dos directores de fotografia na produção cinematográfica são muitas vezes desconhecidos do grande público cinéfilo". Nomes como Acácio de Almeida, Elso Roque, Manuel Costa e Silva, Rui Poças, Michael Ballhaus e Robby Müller, essenciais na cinematografia nacional e mundial foram algumas das personalidades com quem o ele trabalhou.

3 João Abel Aboim n.1950, é director de fotografia e colaborou várias decadas na Escola Superior de Teatro e Cinema de Lisboa. 
Raquel Rato: Como foi e é o teu trabalho no cinema?

Acácio de Almeida: No cinema que eu trabalhei sempre houve uma situação de dificuldades. Nunca houve muito dinheiro. Os filmes são o resultado não tanto de um projecto de investimento sobre um produto, mas um filme é aquilo que se pode fazer com os escassos meios financeiros e com uma grande boa vontade e uma grande disponibilidade. $\mathrm{O}$ que não há em meios materiais, é necessário substitui-los por uma dose de invenção...

Abel Aboim: Eu tenho a tua opinião, eu acho que no fundo as coisas acabam por cair sobre ti, isto é, sobre o director de Fotografia. É evidente que os realizadores têm que ceder em muitas coisas, mas no que diz à imaginação, tu é que tens que suplantar todas as dificuldades.

Acácio de Almeida: Tu dizes que sou eu, na qualidade de director de fotografia, mas neste momento estou a falar para outro director de fotografia, portanto partilhas comigo essa situação. Na realidade cai muito sobre nós a responsabilidade de encontrar soluções que possam ajudar a ultrapassar todas as dificuldades que vão aparecendo, quer em relação à luz, quer com o enquadramento, quer com a escolha de um determinado ângulo.

Abel Aboim: Muitas vezes até com a própria equipa...

Acácio de Almeida: Sim, é um trabalho muito complicado. Reportando-me ao trabalho de um director de fotografia, ele é o elemento mais cúmplice do projecto, do realizador e do produtor. Sobre ele passa a esperança e a capacidade de ultrapassar determinadas situações, ao nível de equipa, de filmagens...

Abel Aboim: Uns filmes que me tocaram, foram os trabalhos que tu fizeste com o António Reis ${ }^{4}$. Para mim esses

4 António Reis (1927 - 1991) foi um cineasta e poeta português que se distingue pelo sentido poético da sua obra. É um dos representantes no filme documentário do 
filmes tinham um experimentação que não era vulgar, e muito menos aqui em Portugal, e isso agradou-me imenso. Sei que esses filmes tiveram dificuldades imensas, mas hoje em dia essas dificuldades para ti diminuíram com as novas tecnologias ou não? O que é que achas?

Acácio de Almeida: Estas novas tecnologias facilitamnos um pouco o trabalho. Mas por outro se escasseiam os recursos somos mais objectivos. A mim nunca me seduziu, quando o produtor diz que tem muito equipamento para me oferecer ou uma equipa fabulosa para o trabalho. Não são estes factores que me seduzem para fazer um filme. Para mim interessam-me mais outros aspectos, como por exemplo, quem é a equipa com que eu vou trabalhar, qual a relação que têm uns com os outros. Também como é o realizador. O realizador será alguém que eu conheça, se não é, será alguém que conhece o meu trabalho. Para mim este é o aspecto mais importante.

\section{Abel Aboim: Mas este aspecto é cada vez menos possível...}

Acácio de Almeida: Para mim se me disserem que vou ter um salário fabuloso, ou que vou ter uma actriz fabulosa, mas se nada se articula convenientemente é um desastre. Eu prefiro que haja uma escolha segundo os valores da amizade e profissionais, e o estar à vontade em trabalhar em conjunto.

Abel Aboim: Mas, estás a esquecer uma coisa fundamental para ti, que é os valores estéticos.

Acácio de Almeida: Sim os valores estéticos estão desde o inicio do projecto. O diálogo do realizador e do director de fotografia é muito importante, pois somos nós que vamos definir e querer que o aspecto estético seja interessante. Que haja toda uma pesquisa e um aprofundar, isto é a base da primeira aproximação entre o realizador e o director de fotografia...

movimento do Novo Cinema, que explora as técnicas do cinema directo. 
Não sei se algum dia em contei à Raquel, mas uma vez num filme italiano, com uma equipa fabulosa, com estrelas americanas, enfim uma grande produção (com motorista para o director de fotografia) não me senti nada bem. Houve um momento em que me levantei da minha cadeira para ir corrigir um projector que estava ali ao lado, mas desisti, pois veio logo o director de produção que era um tipo que tinha tudo controlado, e que me pergunta: "Acácio, quantos electricistas precisas mais?". Bom na realidade foi chamar-me à atenção que estávamos num projecto em que o director de fotografia não tem que fazer esse trabalho, mas eu fi-lo por uma questão de intuição, porque senti que a luz precisava de uma pequena mudança, uma pequena nuance. $\mathrm{O}$ produtor disse-me que eu não tinha que fazer essas coisas. Esta produtora, produziu filmes do Bertolucci...

Vou-te dar um exemplo, quando fiz o Cerco $^{5}$ em 1970 do Cunha Telles ${ }^{6}$.

Abel Aboim: Esse é o primeiro filme que fizeste como director de fotografia numa longa-metragem.

Acácio de Almeida: Sim, foi. O Cunha Telles falou-me vamos fazer um filme? O problema é que não há dinheiro. E eu,

5 Sinopse, «Lisboa, 1969. Originária da alta burguesia, Marta, de vinte e poucos anos, abandona o marido, em busca de uma condição de vida mais autêntica. Sabe o que repudia, mas sente-se confusa quanto ao que pretende. Hospedeira de terra, modelo de uma boutique, acaba por contactar Vítor Lopes, com problemas económicos. Trata-se de um contrabandista de baixo estofo, que um dia aparece morto no Tejo. Será culpa de Marta, devido a um descuido? Afinal, também para ela os dados estão lançados: continua só, mas também mais lúcida e responsável...». José de Matos-Cruz (1999). O Cais do Olhar - O Cinema Português de Longa Metragem e Ficção Muda, Lisboa: Cinemateca Portuguesa: 140.

6 Éum cineasta e produtor português, um dos iniciadores do Cinema Novo português, tanto como realizador como produtor. Instala-se em Paris por volta de 1956, e estuda realização no Institut des Hautes Études Cinematographiques (IDHEC). Regressado a Portugal, assume funções directivas nos Serviços de Cinema da Direcção de Geral do Ensino Primário e dirige cursos de cinema na Mocidade Portuguesa. Em 1967 por falta de êxito comercial dos filmes desse novo movimento, abandona por curto período a produção e realiza Cine-Almanaque, jornal de actualidades cinematográficas de que são exibidas doze edições. Nas décadas de 80/90 reinicia a actividade de produtor, contando desde essa data com mais de 50 películas produzidas, de realizadores como Fonseca e Costa, Eduardo Geada, Joaquim Leitão, Edgar Pêra, António de Macedo, António Pedro Vasconcelos, entre vários telefilmes e co-produções internacionais. 
ok! Então a equipa era eu, o electricista e mais um assistente e uma câmara. Mas a dado momento o chefe electricista foime roubado, porque tinha uma boa cara, e acabou para ir para actor do filme. Acabei por ficar eu e o assistente, mas este também era muitas vezes chamado fazer outras coisas. Eu sozinho, com a câmara, com a luz, e ainda para mais com uma câmara que tinha o obturador partido, com uma película velhíssima que tinha oito anos, enfim o filme foi feito com grande contrariedades a nível técnico, mas foi um filme que funcionou muito bem, tendo recebido dois prémios, e que no panorama do cinema português era uma experiência nova. A narrativa retratava uma realidade dos nossos dias...

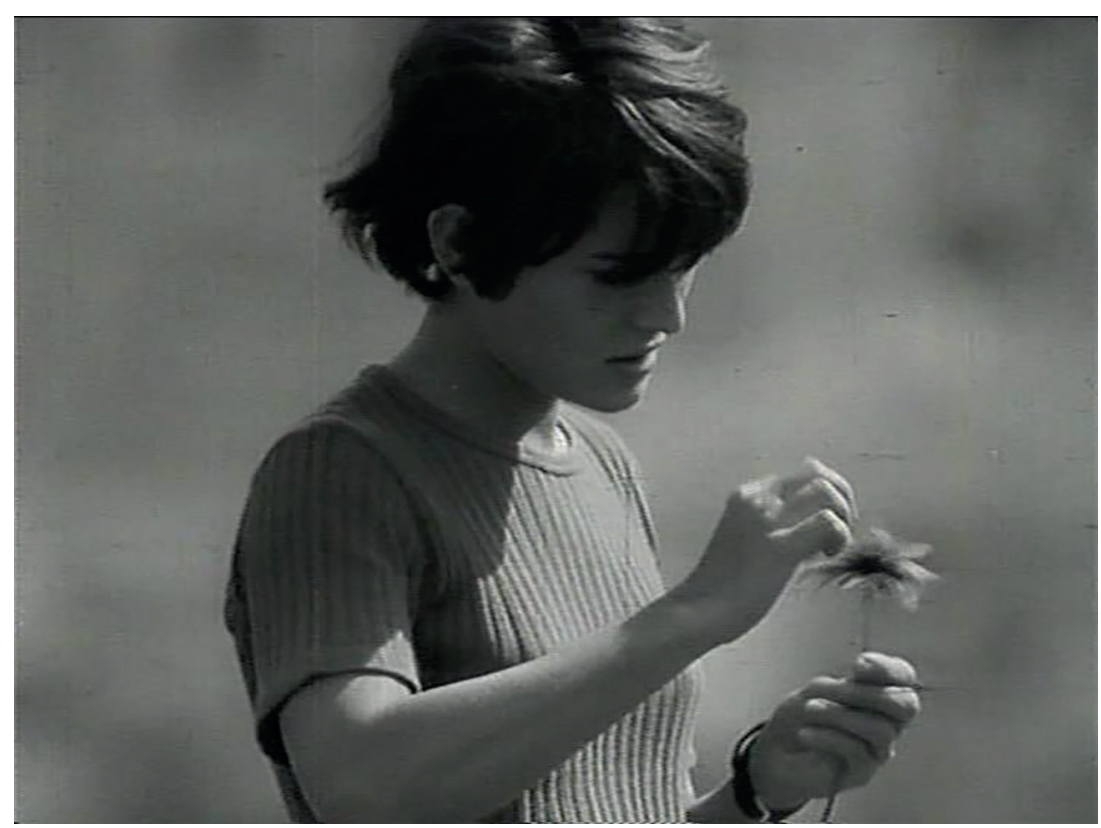

Imagem 2. Fotograma do filme $O$ Cerco, actriz Maria Cabral Fonte: Cinemateca Portuguesa - Museu do Cinema

Abel Aboim: Lembro-me que foi o lançamento da Maria Cabral, que não vinha do métier. Lançou-se uma estrela...

Acácio de Almeida: Sim, fabulosa ... 
Raquel Rato: Pode dizer-se que foi com este filme que se vê a influência da Nouvelle Vague no cinema português?

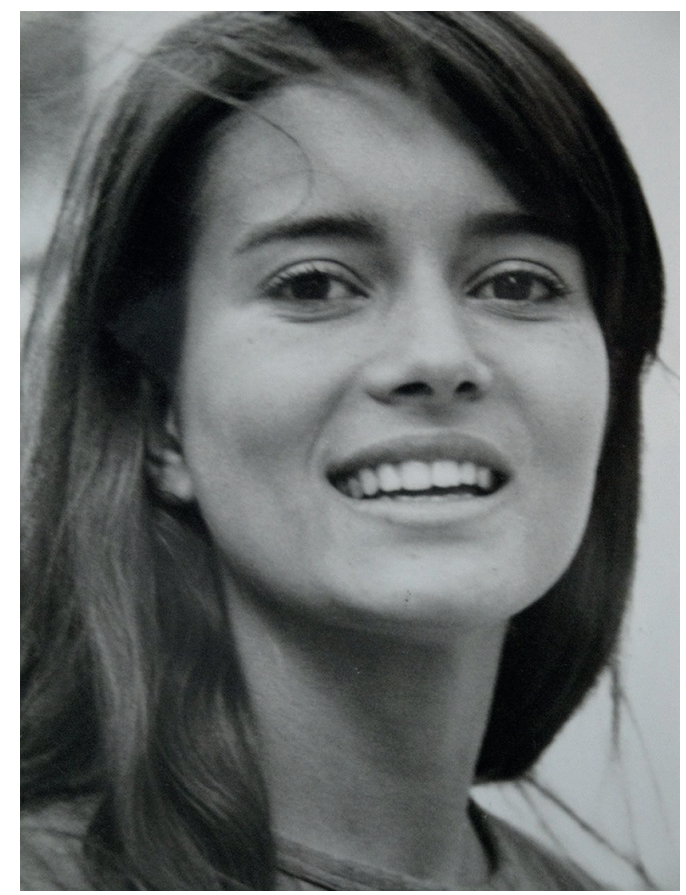

Imagem 3. Actriz Maria Cabral

Fonte: Fotografia do arquivo de Acácio de Almeida

Acácio de Almeida: Já tinha começado antes, com os filmes; "Verdes Anos" (1963) e "Mudar de Vida" (1966) de Paulo Rocha e o "Belarmino" (1964) de Fernando Lopes. São os filmes mais emblemáticos dessa mudança no cinema português. "O Cerco", apareceu mais tarde, aliás o Cunha Telles é que produzia os filmes, ele foi o motor de arranque, foi o dinamizador do cinema. Na altura ele era muito jovem, tinha acabado o curso do IDEC e tinha um desejo muito grande de fazer cinema. Entre outros jovens encontramos os que tinham feito escola fora, com o Paulo Rocha, o Alberto Seixas Santos e o Matos Silva, foi mais tarde. Todos estes procuraram sair para adquirir novos conhecimentos. Nessa altura o Cunha Telles resolve criar a primeira escola de cinema. Creio que funcionou 
três anos. Fez um acordo com os professores do IDEC: eles davam a linha de orientação pedagógica. Cá em Portugal foram seleccionados vários professores que eram examinados pelo IDEC. Os que completassem o $2^{\circ}$ ano, entravam para a escola francesa, o IDEC. Eu não cheguei a ir para o IDEC porque o Cunha Telles convidou-me para ir fazer "As ilhas Encantadas"(1965) de Carlos Vilardebó. Concluindo, o Cunha Telles foi o grande dinamizador em vária vertentes no cinema português. Empenhou-se de tal modo no cinema que queria produzir, mas acabou por falir. Ao longo da sua carreira são falências sucessivas. A história dos produtores contam-se com as falências...

Abel Aboim: Tu mais tarde foste fundador do $\mathrm{CPC}$ (Centro Português de Cinema) que importância é que achas que isso teve para o cinema português?

Acácio de Almeida: O CPC foi a forma de oficializar um grupo de pessoas que queria trabalhar em cinema, sobretudo com o apoio de uma instituição prestigiadora e que nos honrava, a Fundação Calouste Gulbenkian ${ }^{7}$. Assim já não éramos os "maluquinhos" que andavam a fazer coisinhas, mas éramos assim um grupo que muitas instituições ligadas à arte que davam o seu aval.

Abel Aboim: Até porque vocês juntaram-se com ruptura para com o cinema que existia....

Acácio de Almeida: Sim, o cinema que existia era apoiado pelo chamado o Serviço Nacional de Informação, e que privilegiava, quer o teor dos trabalhos que eram mais de acordo com a politica vigente. $\mathrm{Na}$ altura fazíamos um ou dois filmes por ano. Fazia-se um jornal de actualidade, documentários

7 A Fundação Calouste Gulbenkian é uma instituição portuguesa sem fins lucrativos criada com bens do mecenas Calouste Gulbenkian a partir de disposição testamentária. Após a sua morte, em 1955, legou os seus bens ao país sob a forma de uma fundação. A fundação apoia muitas actividades culturais e possui uma orquestra, bibliotecas, um coro, salas de espectáculos e dois museus (arte antiga e contemporânea) com cerca de seis mil peças no seu acervo. 
promocionais de turismo, enfim a actividade era muito pequena. Chegamos de facto a um momento de ruptura, do antigo cinema, mas nós também não sabíamos o que fazer, porque havia por detrás uma cultura mais cineclubista... Estávamos cheios de vontade de trabalhar, mas não havia apoio, tanto a nível de infra-estruturas, como laboratórios muito fracos, enfim, havia muito pouco. A minha geração, eu o Elso Roque, o Costa e Silva, foram os que mantiveram entusiasmo "uma chama acesa", e também como é evidente os realizadores, os assistentes ..... que é culminado com o primeiro filme do Paulo Rocha e por aí em diante, com outros filmes... "O Passado e Presente" (1970) do Manoel de Oliveira, onde colaborei como director de fotografia.

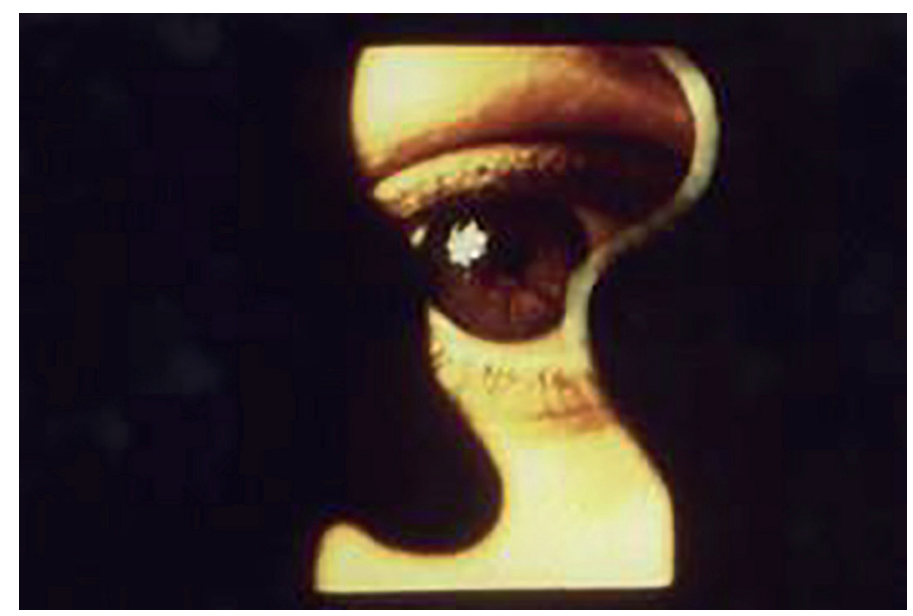

Imagem 4. Fotograma do filme $O$ Cerco criado por Acácio de Almeida (cartão preto recortado em forma de fechadura ${ }^{8}$

Fonte: Cinemateca Portuguesa - Museu do Cinema

Abel Aboim: Daí a importância do CPC.

Acácio de Almeida: Sim foi uma forma de ganharmos força institucional para trabalharmos. Foi positivo também

8 Esta imagem só foi possível graças à criatividade de Acácio de Almeida. Era necessário fazer um plano em que a personagem espreitasse numa fechadura. Como a dificuldade era significativa, Acácio de Almeida recortou um cartão preto e colocou-o à frente da objetiva da câmara para recriar assim uma fechadura. 
porque abriu as portas a outras gerações. Éramos os "Dons Quixotes" do cinema.

$\mathrm{Na}$ maior parte dos filmes eu tive sempre uma intervenção, não só ao nível da estética e narrativa do filme, mas também na solução de problemas em situações técnicas. Recordo que no filme "Dino e Django" da Solveig, crie uma grua muito artesanal e numa determinada situação não tinha acesso à câmara, isto é, não podia ver a imagem. Fiz então um visor electrónico que me permitia ver a imagem, mas de uma forma muito rudimentar. No fundo era uma realização pessoal, mas a outro nível, diz-se que "a forma aguça o engenho e a necessidade cria", e eu sentia necessidade de equipamentos, mas como não os tinha, criava-os. Hoje ainda continuo a fazêlo, julgo que é o meu lado jovem, a manutenção do meu sonho. E com este exercício regresso à alegria da minha infância, são formas de estarmos bem, connosco...

Raquel Rato: Sei que já trabalhaste com digital. Gostaria de saber o que é que tu achas sobre as novas tecnologias e de que modo afectam o teu trabalho com director de fotografia?

Acácio de Almeida: $\mathrm{O}$ cinema ao longo da sua historia teve várias evoluções, com a descoberta dos Irmãos Lumière, o cinema começou por ser um entretenimento de feira, com o seu lado mágico, pois reproduzia o movimento, depois, verificou-se que isso poderia ir mais longe, como contar pequenas histórias. As câmaras mais evoluídas já têm capacidade de levar rolos maiores, as ópticas foram sendo aperfeiçoadas, depois vêm os travellings, as panorâmicas .... no fundo a linguagem do cinema evoluiu pelo facto de haver necessidade de contar as histórias de uma forma diferente. Tivemos o cinema mudo, o sonoro e o cinema a preto e branco, tudo isto de uma forma mais ou menos pacifica. Para mim o cinema que nos influenciou a todos nós foi o cinema mudo. Com o aparecimento do cinema a cores, houve uma reacção diferente, pois com a cor no cinema, já não há uma distinção ou separação do que é a realidade, o mistério do preto e branco acabou. Com o preto e branco era mais fácil transportarmo-nos para um imaginário. A cor pelo 
contrario está muito próximo do realismo, mas rapidamente o cinema foi aceitando a diferença, até os filmes tinham o mesmo processo de construção, com a diferença que a cor começou a ser trabalhada de outras formas. Para mim a cor veio trazer uma mais valia para o cinema, pois seria mais um elemento de expressão narrativa.

Raquel Rato: Quando começaste a trabalhar nos filmes a cores falavas com o realizador sobre pormenores que tu achasses importantes em relação ao décor? Ou era o decorador é que se ocupava sempre nestas questões?

Acácio de Almeida: Era mais quem fazia o décor que obedecia a outro tipo de informações, mas a cor e a sua utilização começou também a ter o seu tempo de aprendizagem. A própria tecnologia da cor foi melhorando cada vez mais de forma a poder traduzir a cor real ou pelo contrario, no sentido de podermos alterar a cor segundo os objectivos desejados na estética do filme, ou no interior da narrativa. E isso só foi possível quando começou a haver todo um processo sobre a cor, ou seja, plano a plano serem equilibrados. Retirar ou introduzir dominantes, são processos que levaram muito tempo e que a meu ver, hoje, atingiram o seu grau de evolução máxima. Entretanto aparecem as novas tecnologias, que é o digital, mas que não interessou muito o cinema. Só a partir de uma determinada altura é que se começou a mostrar interesse pelas novas tecnologias, por exemplo, quando as televisões começaram a dominar o mercado do cinema e constataram que precisavam do cinema para preencher as suas horas de programação, então os operadores de televisão deram-se conta de que era importante estarem na produção dos filmes com pequenas participações que ajudavam imenso a produção. É de tal modo grave e forte essa presença que a partir de uma determinada altura nenhum filme se fazia sem a participação da televisão, participação essa, que se mantém até hoje, sobretudo falando do cinema português.

Com a evolução do digital e com os suportes de alta definição os profissionais começaram a ver que afinal, filmar neste meio também poderia ser interessante e isso com custos 
muito mais baixos. No orçamento de um filme o custo da película tinha uma valor muito importante, muitas vezes o orçamento total do filme era posto em causa, pois quanto mais se filmava maior iria ser o custo do laboratório. Com o aparecimento deste sistemas que, gravam em digital com um custo muito mais reduzido e com um processo similar ao da película...

Raquel Rato: Achas que podemos comparar este cinema digital, onde poderá existir uma equipa reduzida com os filmes do início da tua carreira?

Acácio de Almeida: Sim, penso que é idêntico, porque quando eu fui para Trás-os-Montes com o António Reis e a Margarida Cordeiro, e onde a equipa era constituída por mim, o Carlos Mena como assistente e o João Silva como electricista. Íamos todos numa carrinha, onde atrás ia o equipamento o António Reis a Margarida Cordeiro, a filha e Umbelina. Usava, neste filme uma câmara Curtain, Éclaire, um tripé e um gerador de 4 kilowatts, meia dúzia de pequenos projectores. Foi com este material que se fez o filme. Neste filme havia muita liberdade devido ao facto de a equipa ser muito reduzida e daí nos podermos deslocar a sítios muito facilmente. Durante uma semana fomos há mesma hora e ao mesmo local para filmar um plano. Hoje seria impensável fazer isso, a atitude pode ser a mesma, mas o suporte variou... $\mathrm{O}$ que por vezes se confunde é que pelo facto de se ter um suporte ligeiro, qualquer pessoa pode filmar e isso é um erro, porque não se deve filmar e realizar um filme sem haver reflexão e esse é o grande risco. Da mesma maneira que também podia acontecer com a película, mas como esta é mais cara, obrigávamo-nos a reflectir na melhor utilização desse recurso que era a película. Se o HD for utilizado com a mesma atitude com que se faz em cinema, podemos fazer um filme com reflexão. Não é o suporte que vai alterar o trabalho final. Até se estivermos numa grande produção a atitude tem de ser a mesma. Agora põem-se alguns problemas o que diz respeito à duração, isto é à longevidade do suporte de gravação. Ainda não há muita experiência, no inicio dizia-se que o digital é eterno, mas verifica-se que não é bem assim e hoje está-se 
a chegar à conclusão que o fotossensível dura muito mais se este estiver em boas condições de conservação, mas penso que nenhuma teoria é segura, porque é necessário vivê-las, mas não há a certezas... Sabemos que o cinema percorreu 50 ou 60 anos e que muitos suportes foram duradouros, em relação ao digital é tudo muito recente.

Banaliza-se o digital quando não há uma reflexão do que se vai fazer. Por exemplo há condicionantes fortes ao nível da tradução dos valores luminosos que provocam comportamentos diferentes ao nível do digital e no fotossensível. A latitude de exposição no fotossensível é muito maior do que no digital, e uma vez conhecendo esse fenómeno é possível obter toda a gama de valores cromáticos, quer no digital, quer no fotossensível. O que é necessário é conhecer o comportamento do digital para trabalhar em conformidade. É muito mais critico trabalhar em digital com luzes muito fortes. Portugal é um país com forte valor lumínico de luz, tem uma atmosfera sempre muito limpa devido aos ventos do atlântico. Por isso a luz é de grande intensidade e contrastes muito grandes.

Raquel Rato: Achas que a luz de Portugal é mais difícil de filmar em comparação com muitos países onde já filmaste?

Acácio de Almeida: Nos países do norte a luz é sempre muito equilibrada, com uma luz muito doce, muito suave e por vezes a luz do interior é igual à do exterior. Não temos grandes problemas de iluminar, isto mesmo durante o dia, quando é o final do dia podemos passar do interior para o exterior pois não há contraste. Aqui em Portugal, temos um céu muito limpo e o sol directo provoca sombras muito densas com recortes muito grandes, mas que convenientemente podem ser utilizadas de uma forma de expressão artística, mas não há uma fonte de luz artificial que possa equilibrar essa luz. Quando trabalho em exterior trabalho com o sol tal como ele está, posso eventualmente utilizar algum reflector com um tamisador frente ao sol para suavizar, diminuindo a intensidade provocando alguma reverberação geral para que a luz seja mais doce, ou então trabalho com grande contraste. Aqui em Portugal o digital não é bom, pois dá-se a alta luz 
e também não vai dar a baixa luz pois colocam-se grandes problemas. Apanhar o eixo do sol, a luz fica sem modelação, portanto filmar a 45 graus talvez seja a situação melhor, mas se houver mais luz é necessário tamisar, isto é, por um tamisador, uma gaze branca, uma malha mais ou menos apertada que faz difundir a luz, dando-nos sombras menos nítidas. Ao difundir a luz, ela provoca reverberações em todos os sentidos deixando de ser uma luz direccional, passando ser uma luz, dispersa, pulverizada. Assim, já podemos com outro reflector suavizar um bocadinho mais evitando o valor muito alto. Existem câmaras que comportam, isto é, fazer uma curva muito mais baixa de maneira que os picos não sejam tão elevados.

Raquel Rato: Voltando um pouco atrás, quando falámos sobre a cor e a influência no cinema de outras artes, como a pintura, tu como director de fotografia, achas que o cinema de agora abandonou ou não essa via?

Acácio de Almeida: Sim, o cinema em determinado momento procurou aproximar-se da pintura e só o pode fazer porque delimitava o seu espaço a um quadro. Dentro desse quadro organizava os vários elementos. Só que há uma diferença muito grande, primeiro o cinema não é só expressão artística é também essencialmente uma expressão narrativa, é o contar de uma história e nem sempre podemos atender a todos os aspectos estéticos em relação aos aspectos narrativos e isto porquê? Porque quando organizamos um quadro, e este é fixo nós podemos por os valores e as linhas de força, os equilíbrios e a composição que entendermos, mas a partir do momento em que no interior do quadro há um personagem que se desloca, cria-nos alguns problemas, pois a composição do quadro já mudou. Ao deslocar-se ele vai desequilibrar todo o valor cromático da luz que existia, vai por exemplo criar sombras se ele estava iluminado, estas sombras podem ser boas esteticamente ou não. Tudo tem que ser considerado: onde filmamos, quais são os movimentos do actor e como é que podemos por a luz de forma a que seja harmoniosa, isso é um aspecto para um quadro fixo. 
Abel Aboim: Aliás isso é interessante porque é exactamente a grande diferença entre a imagem fixa, a fotografia, e o cinema, porque tecnicamente tudo é igual.

Acácio de Almeida: A fotografia é o instantâneo, o momento, o cinema é mais do que isso, é a continuidade do momento. Se adicionarmos a este aspecto os movimentos de câmara aí temos vários problemas. Como harmonizar constantemente um quadro que está em movimento com actores no seu interior que se cruzam num décor? Como fazer isto tudo dando-lhe um valor estético? Em geral num filme ninguém pensa nestes aspectos, pois o realizador diz sempre que isto é um trabalho do director de fotografia.

Abel Aboim: Por isso é que é importante trabalhar com realizadores que tenham alguma noção de como é que as coisas funcionam ao nível da imagem, porque há realizadores que não têm essa noção, sabem o que querem, mas a partir daí não sabem mais nada. Trabalhar com um realizador que tem alguma noção facilita bastante.

Acácio de Almeida: Sem duvida. E depois põem-se outros problemas, como a capacidade que as pessoas têm de se adaptar rapidamente a uma situação de improvisação e de não entrar em pânico. Dominar a situação.

Abel Aboim: Isto leva-me a pensar uma questão muito importante que é uma coisa essencial no cinema, é que o cinema é um trabalho de equipa e há uma coisa que me fascina muito e sempre me fascinou na fotografia, é que o director de fotografia é também uma espécie de psicólogo porque tem que lidar com uma equipa que muitas vezes é muito vasta, para além de ter de colaborar com os outros sectores, a realização, produção, montagem etc...

Acácio de Almeida: E estar à escuta do realizador, o que é que ele quer, e saber quando não diz nada saber o que ele pretende... 
Abel Aboim: Ora isto implica que um director de fotografia tenha a capacidade de se aperceber de tudo, a equipa, dos meios etc, que tenha uma coisa que eu sempre apreciei no Acácio, a calma, nem que esta seja aparente, porque se os directores de fotografia não controlarem o lado emocional deles e dos outros é o suficiente para estragar um filme.

Acácio de Almeida: Sim, o director de fotografia é um chefe de equipa alargado a quem o realizador deposita confiança. Muitas vezes aconteceu-me o seguinte, o realizador dizia-me: "vai iluminado enquanto eu escrevo a cena"...

\section{Raquel Rato: O cinema colectivo é possível?}

Acácio de Almeida: Teoricamente ele é possível, mas na prática não. Se envolve um grande número de pessoas e a decisão se estende a todas essas pessoas, chegamos a um momento em que o impasse é muito grande, porque nesse número de pessoas haverá muita gente que tem uma visão diferente. Como fazer, como agir, como enquadrar tudo o que se relaciona com a mise-en-scène, com os diálogos, com a posição da câmara, como conjugar todos estes factores, para mim não há solução. Após o 25 de Abril houve alguns filmes feitos com o rótulo de trabalho colectivo e pode não estar desajustado esse rótulo porque engloba a participação de várias pessoas, mas são mais filmes de reportagem. No fundo, se analisarmos bem, houve um elemento aglutinador no final que foi o montador. Quando avançamos para estruturas mais aprofundadas, aí, o que se costuma fazer é descentralizar e por vezes temos um filme com dois autores. Podemos dizer é que a participação num filme é que é sempre colectiva. Um filme colectivo pressupõe que todas as decisões tenham sido tomadas em conjunto, quando na realidade não é. O colectivo dá a sua prestação orientada pelo realizador.

Raquel Rato: Podemos dizer que quando trabalhaste com o António Reis era um cinema colectivo?

Acácio de Almeida: Na altura, posso dizer que era colectivo, pois a experiência do António Reis e da Margarida 
Cordeiro era pouca e apoiaram-se na experiência profissional que eu tinha. A direç̧ão ela existiu, na medida em que houve uma escolha de décors, houve uma escolha de actores, de uma história, inclusive e escolha de um director de fotografia, portanto ele é, o filme, colectivo na medida em que sintetiza o trabalho de várias pessoas, mas mesmo se ouviram muitas opiniões minhas, não deixa de ser um trabalho com uma estrutura pessoal muito forte. Mesmo que eu tenha tido uma componente muito forte, o filme é essencialmente uma ideia deles o dois, a forma como depois montaram. A minha participação nesse filme é muito grande, ao nível de procura de imagens... de tudo aquilo que é permitido a um director de fotografia que é ajudar o realizador a ultrapassar dificuldades técnicas que possa ter. A ideia, execução e trabalho final compete-lhe a ele, sem dúvida.

O trabalho do director de fotografia é criativo de grande interesse na construção de um filme, nem sempre é valorizado, mas que a meu ver nos últimos tempos tem ganho um protagonismo e relevo. Acho que o director de fotografia é um dos participantes na construção do filme e que sobre ele cai a responsabilidade de que o trabalho dos outros esteja reflectido no filme, pois é ele que sintetiza todo o trabalho técnico do filme, e ele tem que estar à altura de tudo isso valorizando todos as áreas de que é composto um filme. Penso que o nosso trabalho deve ser reconhecido oficialmente. No que me toca, sinto-me gratificado no acto de fazer. Gratificação maior do que o vencimento que recebo é o acto de fazer, a satisfação que eu tenho por de trás de uma câmara quando a câmara começa a filmar. Os actores a interpretar e onde se cria uma tensão no plateau, um silêncio, isso é um momento mágico de que me alimentei muitos anos e que me acabou por viciar, sou um viciado nesse momento.

Depois para mim a partir do momento que o filme está na lata já me basta, mas é óbvio se o filme mais tarde é bem sucedido fico muito satisfeito...

Raquel Rato: Gostaria de agradecer aos dois por terem partilhado o vosso conhecimento nesta entrevista. 